\title{
Experimental Study of Ignition and Flame Characteristics of Surrogate of Cracked Hydrocarbon Fuels in Supersonic Crossflow
}

\author{
Liuwei Cheng ${ }^{1}$, Fengquan Zhong ${ }^{-1,2}$, Zhipu Wang ${ }^{1}$, Hongbin $\mathrm{Gu}^{1}$, Sugang $\mathrm{Ma}^{1}$, Xinyu \\ Zhang ${ }^{1,2}$ \\ (1. State Key Laboratory of High Temperature Gas Dynamics, Institute of Mechanics, Chinese Academy \\ of Sciences, Beijing 100190, China) \\ (2. School of Engineering Science, University of Chinese Academy of Sciences, Beijing 100049, China)
}

\begin{abstract}
The ignition and flame characteristics of ethylene and blend fuel (surrogate of thermal cracked kerosene) are studied experimentally on a direct-connect supersonic combustor facility. The blend fuel consists of $\mathrm{H}_{2}, \mathrm{CH}_{4}, \mathrm{C}_{2} \mathrm{H}_{4}, \mathrm{C}_{2} \mathrm{H}_{6}, \mathrm{C}_{3} \mathrm{H}_{6}$ and $\mathrm{C}_{3} \mathrm{H}_{8}$ with molar fractions according to the result of gaseous compositions of thermal cracked kerosene. $\mathrm{CH}^{*}$ luminance in the combustion is filmed by a high-speed camera, and unsteady process of ignition as well as flame formation and proportion is captured. Meanwhile the image of $\mathrm{CH}^{*}$ luminance is one-dimensional treated along the axis of combustor and the relative amount of heat release rate of combustion is obtained. The experimental results show that with equivalence ratio increasing the flame of ethylene is changed from the cavity stabilization mode to the jet-wake stabilization mode and the combustion efficiency increases. In contrast, the total heat release and combustion efficiency of the blended fuel decrease.
\end{abstract}

\section{Nomenclature}

$=$ equivalence ratio

$=$ time

$=$ location

\section{I . Introduction}

Supersonic combustor is one of the key components of propulsion system of air-breathing hypersonic vehicle, and its ignition performance and heat release distribution are critical parameters for evaluation and optimization of engine performance. Under flight conditions of high Mach number, as the result of high total temperature of the inlet air stream and the heat release in the combustor, severe thermal load on the inner wall of the engine brings a challenge for thermal protection of engine structure. At present, regenerative cooling is one of the most effective cooling technologies for hypersonic vehicle and scramjet. Due to high density, high heat value and good stability, hydrocarbon fuels with large molecules such as aviation kerosene are used as the ideal fuel of scramjet. Before being injected into combustor for burning, kerosene absorbs heat from the engine structures and its temperature may rise to very high values with significant pyrolysis. At the flight condition of high Mach number, the regenerative kerosene may be cracked into small molecular hydrocarbons (e.g., $\mathrm{CH}_{4}$, $\mathrm{C}_{2} \mathrm{H}_{4}, \mathrm{C}_{2} \mathrm{H}_{6}$, etc.) and hydrogen before entering combustor. For example, Huang et al. [1] applied surface catalysis technique to study the cracking characteristics of JP-8 fuel at high temperatures. The experimental data showed that the gaseous cracking products include $\mathrm{H}_{2}$ in about 7 mole percent, $\mathrm{CH}_{4}$ in about $34 \%, \mathrm{C}_{2} \mathrm{H}_{4}$ in about $16 \%, \mathrm{C}_{2} \mathrm{H}_{6}$ in about $19 \%, \mathrm{C}_{3} \mathrm{H}_{6}$ in about $10 \%$ and $\mathrm{C}_{3} \mathrm{H}_{8}$ in $8 \%$. The thermal cracking characteristics of China No.3 aviation kerosene were studied by Zhong, et al. [2]. Chromatography was applied to obtain compositions

Corresponding author, email: fzhong@imech.ac.cn 
of the gaseous cracking products at the temperature of $878 \mathrm{~K}$, which consist of $\mathrm{H}_{2}$ in about 7 mole percent, $\mathrm{CH}_{4}$ in about $25 \%, \mathrm{C}_{2} \mathrm{H}_{4}$ in about $18 \%, \mathrm{C}_{2} \mathrm{H}_{6}$ in about $18 \%, \mathrm{C}_{3} \mathrm{H}_{6}$ in about $15 \%$ and $\mathrm{C}_{3} \mathrm{H}_{8}$ in about $11 \%$. Thus the main gaseous cracking products of hydrocarbon fuels are usually small molecular hydrocarbons such as $\mathrm{H}_{2}, \mathrm{CH}_{4}$, $\mathrm{C}_{2} \mathrm{H}_{4}, \mathrm{C}_{2} \mathrm{H}_{6}, \mathrm{C}_{3} \mathrm{H}_{6}, \mathrm{C}_{3} \mathrm{H}_{8}$, et al. with a total molar fraction larger than $90 \%$.

As one of the most representative cracking products, ethylene is chosen firstly to study the ignition and flame characteristics. Then, to study ignition and flame characteristics of cracking products of large molecular hydrocarbons, blended hydrocarbons are chosen as surrogate of the cracking products of kerosene. The blended fuels consist of $\mathrm{H}_{2}, \mathrm{CH}_{4}, \mathrm{C}_{2} \mathrm{H}_{4}, \mathrm{C}_{2} \mathrm{H}_{6}, \mathrm{C}_{3} \mathrm{H}_{6}$ and $\mathrm{C}_{3} \mathrm{H}_{8}$. The compositions of blended fuels are based on the gaseous cracking products of PR-3 kerosene at different temperatures as described in our previous work [2].

Images of $\mathrm{CH}^{*}$ luminance are recorded by a high-speed camera and a band-pass filter and used to study ignition and flame propagation of fuels in a Mach 2.5 supersonic crossflow. The distribution of relative heat release rate along the axis of combustor is obtained, and effects of fuels and equivalence ratio on ignition, flame characteristics and heat release distribution are discussed.

\section{Experimental Setup}

It is very difficult to directly measure heat release rate in supersonic combustor. One of the most effective methods is to determine heat release rate by measuring other flow quantities which are correlated to it. $\mathrm{CH}^{*}$ is an important intermediate product of combustion of hydrocarbon fuels and the visible light of $430 \mathrm{~nm}$ is emitted by $\mathrm{CH}^{*}$ in transitions from the excited state to the ground state. $\mathrm{CH}^{*}$ luminescence has been used as a reliable marker of heat release rate in flames by many researchers [3-6]. Thus the concentration of $\mathrm{CH}^{*}$ can be qualitatively characterized by the gray value of image of $\mathrm{CH}^{*}$ luminescent intensity and the distribution of relative heat release rate can be referred. The method is also be applied to obtain the evolution process of $\mathrm{CH}^{*}$ concentration in the ignition and combustion of the blend fuel.

Fig. 1 is the schematic diagram of imaging the $\mathrm{CH}^{*}$ luminescence. The luminescence is captured from the observation window on the side wall, and the gray value of the obtained image reflects the integration value of the $\mathrm{CH}^{*}$ concentration along the spanwise direction of combustor (z direction). Integrating the gray value along the height direction of combustor (y direction), that is one-dimensional treatment of luminescent intensity along the axis of combustor, the distribution of relative heat release rate along the axis of combustor can be determined.

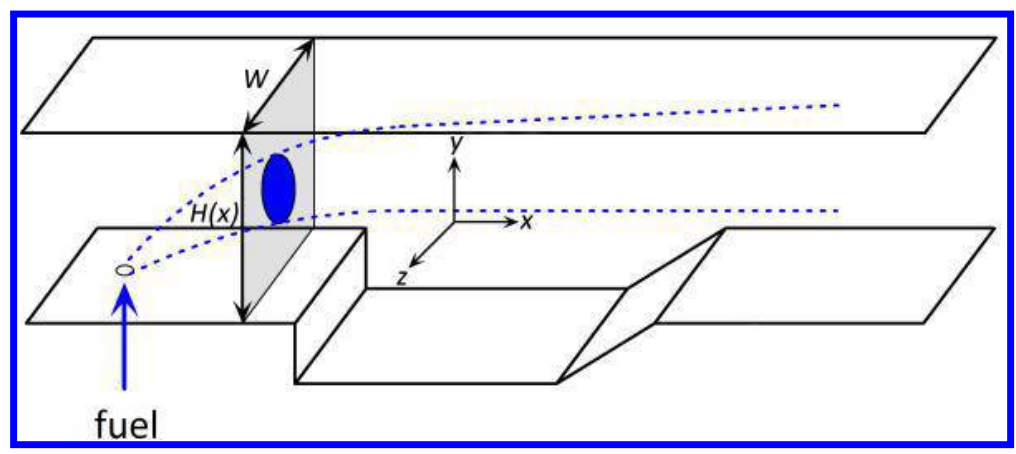

Fig. 1 Schematic diagram of imaging the $\mathrm{CH}^{*}$ luminescence

Experiments are conducted on a direct-connect supersonic combustor facility as shown in Fig. 2. The geometry of the facility has been described in details in our previous work [7]. The vitiated air flow is generated by hydrogen/air combustion and then accelerates to supersonic speed via sonic nozzle. The two red boxes are observation windows with silica glass from which the $\mathrm{CH}^{*}$ luminescence is captured. A high-speed camera and a band-pass filter (central wavelength $430 \mathrm{~nm}$, bandwidth $\pm 15 \mathrm{~nm}$ ) are used to image the luminescence with a frame rate of $10000 \mathrm{fps}$, an exposure time of $1 / 16000 \mathrm{~s}$ and a resolution of $1280 * 240$. 


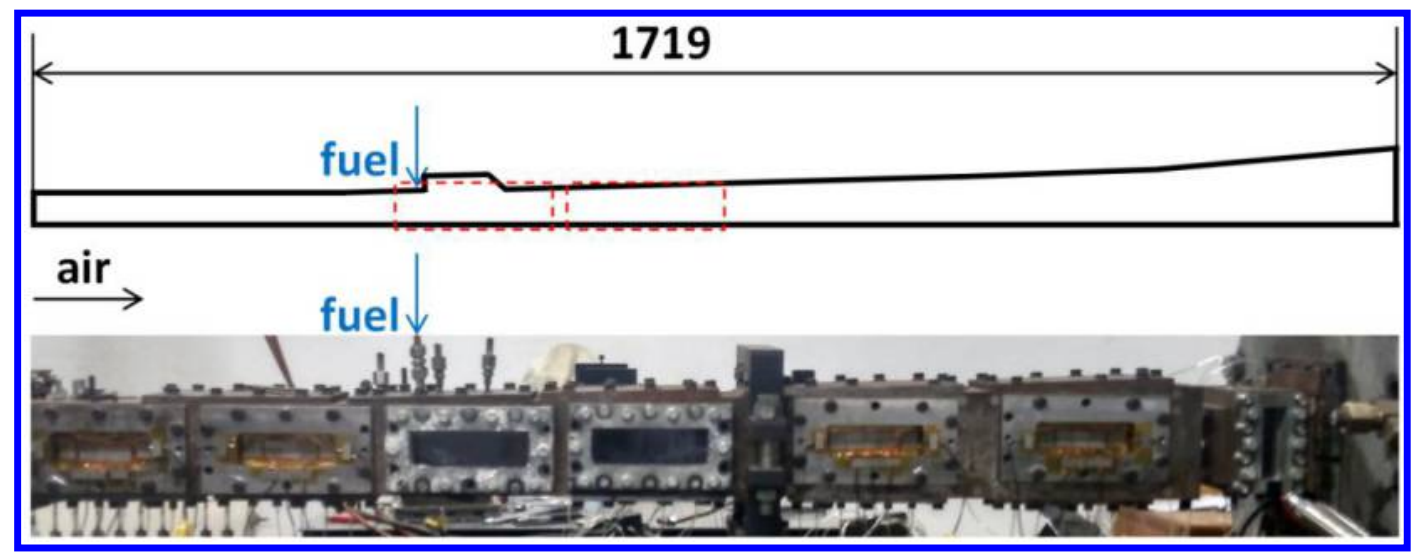

Fig. 2 Direct-connect supersonic combustor facility

As show in Table 1, two fuels are studied in the paper. The first is ethylene which is one of the most representative cracking products especially for optimized catalytic cracking. The second consists of six hydrocarbons and the molar ratio of each composition is given in Table 1.

Table 1 Fuels and the molar ratio of each composition (unit: \%)

\begin{tabular}{ccccccc}
\hline fuel & $\mathrm{H}_{2}$ & $\mathrm{CH}_{4}$ & $\mathrm{C}_{2} \mathrm{H}_{6}$ & $\mathrm{C}_{2} \mathrm{H}_{4}$ & $\mathrm{C}_{3} \mathrm{H}_{8}$ & $\mathrm{C}_{3} \mathrm{H}_{6}$ \\
\hline
\end{tabular}

A

100

11

38

17

12

8

The inlet total temperature of the combustor is approximately $1830 \mathrm{~K}$, the inlet Mach number is 2.5 and the inlet mass flow rate is $1.35 \mathrm{~kg} / \mathrm{s}$. The inlet vitiated air consists of oxygen in $21 \%$, nitrogen in $55 \%$ and water vapor in $24 \%$. As shown in Fig. 2, the fuel is injected from 7 small holes (diameter $2 \mathrm{~mm}$ ) evenly distributed on the wall, and the injection position is located $10 \mathrm{~mm}$ upstream of the leading edge of the cavity. The fuel is ignited by the spark plug installed on the center of the bottom of the cavity, and the time of stable combustion is approximately $2 \mathrm{~s}$. The camera begins to work $0.5 \mathrm{~s}$ before the ignition with a total time of $3.7 \mathrm{~s}$, so as to capture the entire process of ignition and flame propagation.

\section{Results and Discussions}

\section{A. Ignition process}

The fuel is injected upstream of the cavity and ignited by spark plug with a spark time of $0.1 \mathrm{~ms}$. The combustion region is mainly located within the two red boxes (especially the first one) as shown in Fig. 2. The ignition process of fuel $\mathrm{A}$ with an equivalence ratio of 0.17 is given in Fig. 3. In the pseudo-color image obtained from the gray scale image, the white line is the border of the actual imaging region and a part of the cavity region.

As shown in Fig. 3, the spark plug begins to work at the time of $\mathrm{t}=0.1 \mathrm{~ms}$ and the high-voltage electric arc lasts about $0.1 \mathrm{~ms}$. The large red area at $\mathrm{t}=0.1 \mathrm{~ms}$ is caused by strong light emitted from the electric arc and reflected by the inner wall. The fuel is ignited on the bottom of cavity where the flow velocity is small and then the flame spreads to the entire cavity at $\mathrm{t}=0.4 \mathrm{~ms}$. At $\mathrm{t}=0.5 \mathrm{~ms}$, the flame spreads downstream of the cavity. As the flame is formed and stabilized at about $t=0.7 \mathrm{~ms}$, the fuel entering the bottom of the cavity becomes less and the flame is developed mainly in the shear layer caused by the interaction of fuel jet and cavity flow.

Fig. 4 gives the ignition process of fuel $\mathrm{B}$ with the same equivalence ratio of 0.17 . The spark plug begins to work at the time of $\mathrm{t}=1 \mathrm{~ms}$. After ignited by the electric arc, the fuel enters the cavity and an initial flame is formed and stabilized at the region of the backward-facing step near the leading edge of cavity for about $2 \mathrm{~ms}$. At the time of $t=4 \mathrm{~ms}$, the flame spreads to the entire cavity. Then the flame spreads downstream of the cavity 
and the tail of the flame is near the right edge of the second widow. The period from the spark plug working to the stable flame of fuel B is far longer than that of fuel A, which is a result of the ignition delay time of fuel B is much longer than that of fuel A.
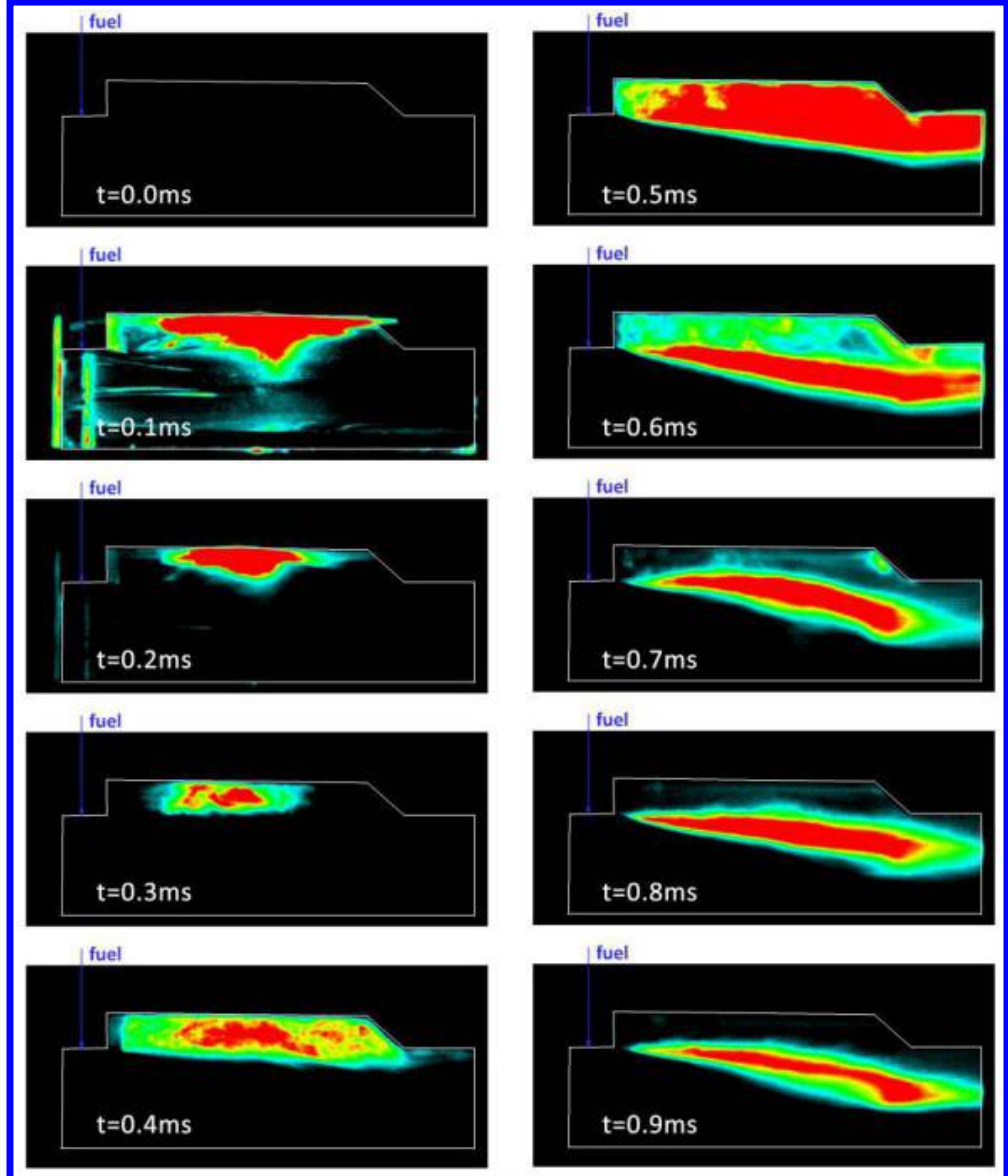

Fig. 3 Ignition process of fuel A with an equivalence ratio of 0.17 


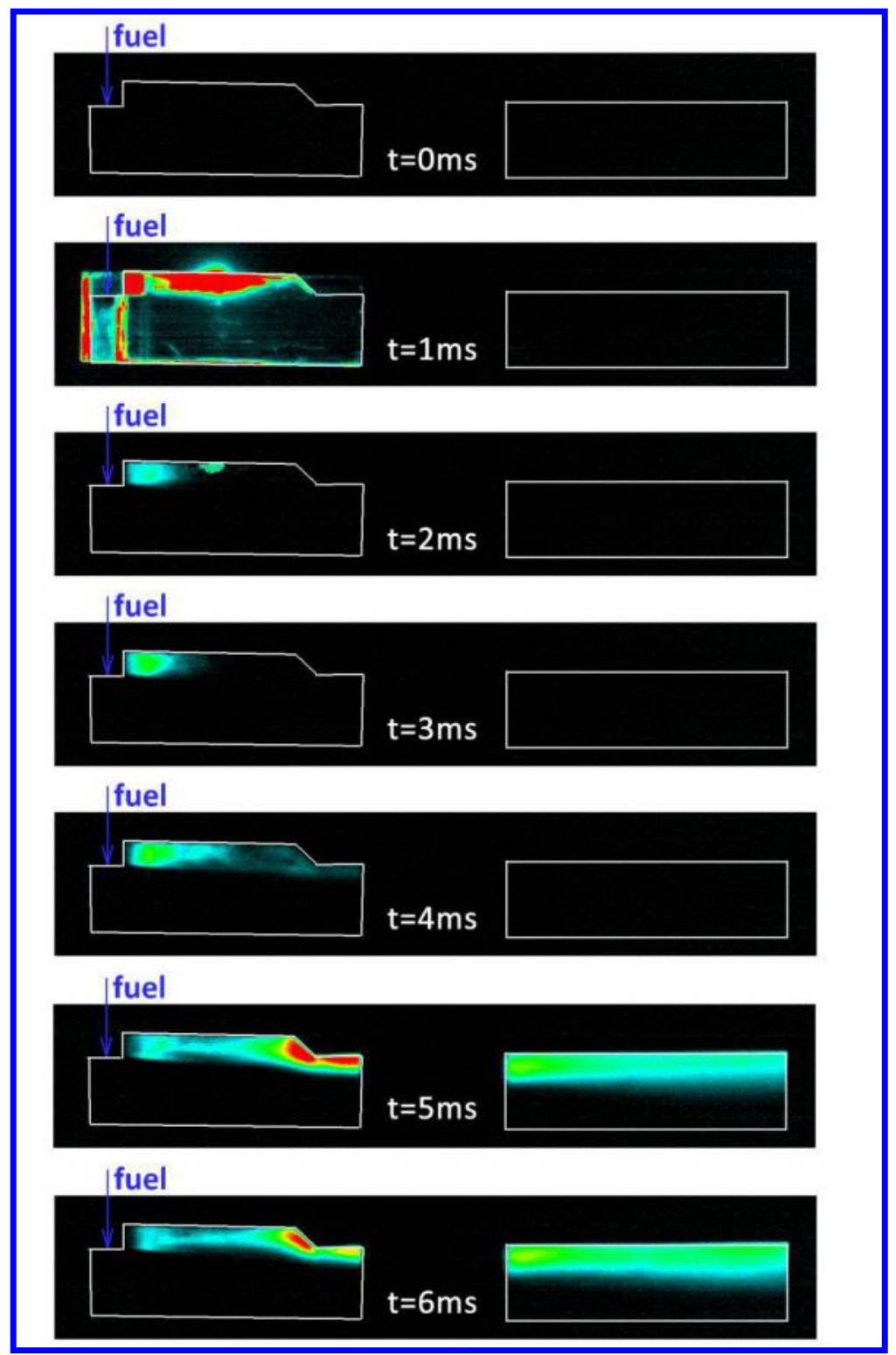

Fig. 4 Ignition process of fuel $B$ with an equivalence ratio of 0.17

\section{B. Flame characteristics and heat release distribution of fuel A}

As discussed before, the ignition process of fuel $\mathrm{A}$ is basically completed at $\mathrm{t}=0.7-0.8 \mathrm{~ms}$. After ignition, the flame has a small-amplitude oscillation around the shear layer. At this condition, the heat release distribution is determined by the mean values of flow parameters averaged within the experimental time. Fig. 5 shows the flame patterns (based on the averaged gray value of $\mathrm{CH}^{*}$ luminescence for a period of 1 second) of fuel A at different equivalence ratios. The legend is the luminous intensity of $\mathrm{CH}^{*}$, which indicates the relative value of concentration of $\mathrm{CH}^{*}$ and the relative amount of heat release rate.

As shown in Fig. 5, at equivalence ratio of 0.14, the flame is stabled around the trailing edge of cavity with a shape of long triangle. With equivalence ratio increasing to 0.17 , the flame extends to the center and the leading edge of the cavity. At higher equivalence of 0.21 , the flame moves forward and spreads into the cavity, and the flame with a more rounded shape is observed. 


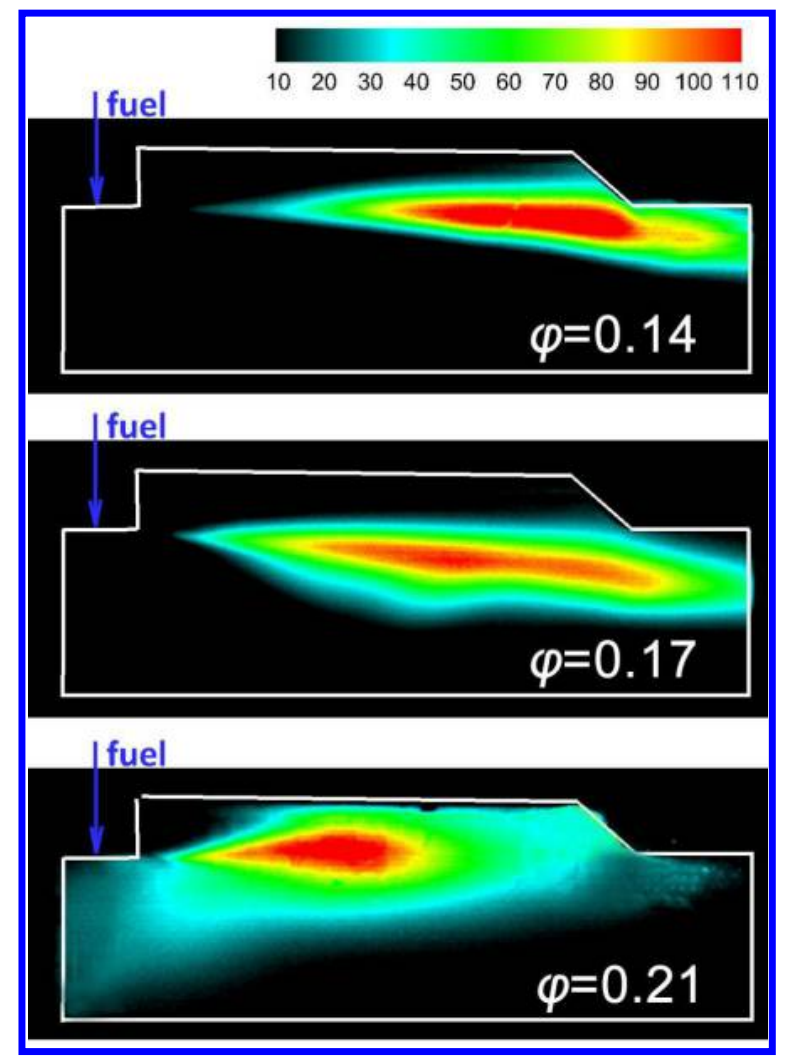

Fig 5. Flame patterns of fuel $A$ at different equivalence ratios

As previously mentioned, distribution of relative heat release rate along the axis of combustor can be characterized by one-dimensional distribution of integration results of gray scale image of $\mathrm{CH}^{*}$ luminescence along the height direction of combustor. Fig. 6 shows distributions of relative heat release rate of fuel A along the axis of combustor at different equivalence ratios. The blue line in the figure shows the structure of the cavity. With equivalence ratio increasing, the peak of heat release rate moves upstream and the total amount of heat release (the area under the curve) increases gradually. Compared to the total amount of heat release at equivalence 0.14 , that at equivalence 0.17 increases $35 \%$ and that at equivalence 0.21 increases $71 \%$, which means the combustion efficiency increases as the equivalence ratio increases.

Fig. 7 gives distributions of wall pressure along the axis of combustor at different equivalence ratios. As discussed above, the peak of heat release moves upstream with the equivalence ratio increasing. The position of wall pressure beginning to rise moves upstream, from the center of cavity to the upstream of the fuel injection point. With the total amount of heat release rate increasing, the peak of pressure at equivalence ratio 0.21 is almost two times than that at equivalence 0.14 . 


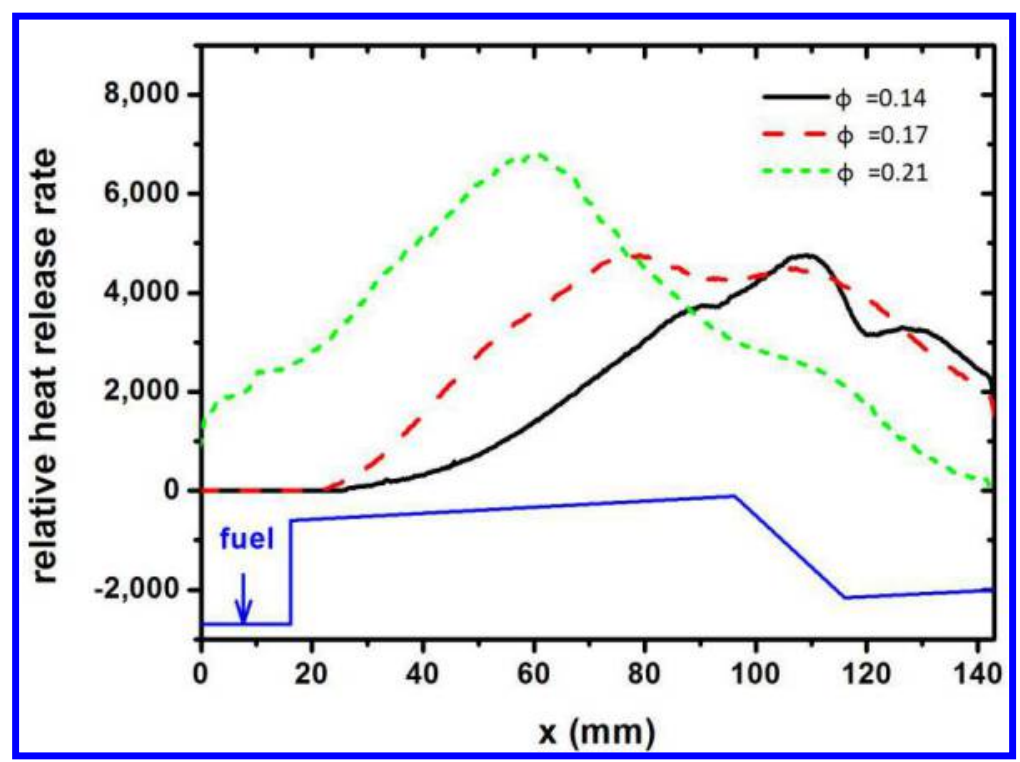

Fig. 6 Distributions of relative heat release ratio of fuel $\mathrm{A}$ at different equivalence ratios

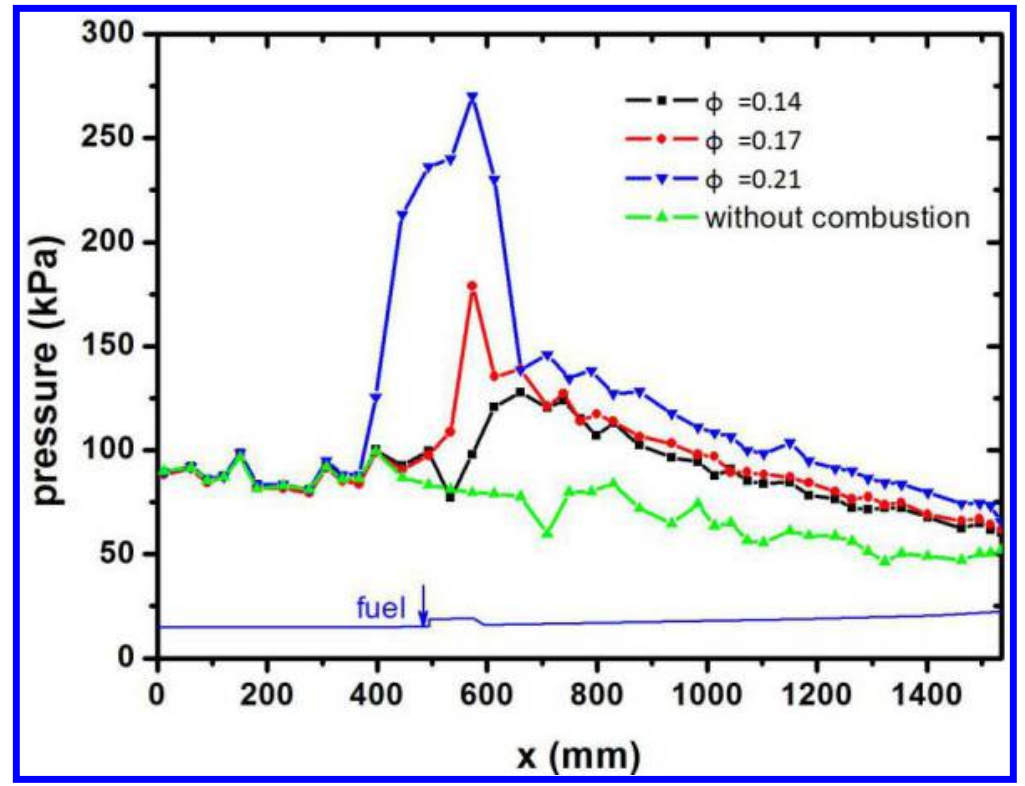

Fig. 7 Distributions of wall pressure of fuel $A$ at different equivalence ratios

\section{Flame characteristics and heat release distribution of fuel B}

Fig. 8 gives the flame patterns of fuel $\mathrm{B}$ at different equivalence ratios. The heat release is mainly distributed at three regions. The first one is the region of backward-facing step of the cavity, at which the velocity is slowed down due to the recirculation zone. The second and the major heat releasing is near the trailing edge of cavity where the combustion is most intense. The third is downstream of trailing edge of cavity, which extends a long distance and even beyond the right edge of the second window. In this region, reaction heat is released gradually. 


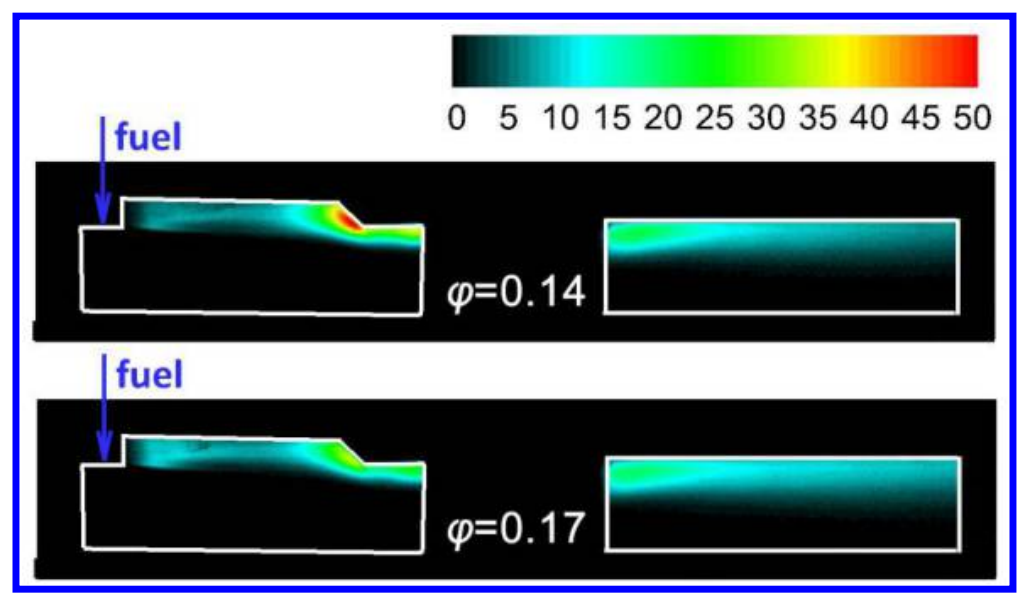

Fig 8. Flame patterns of fuel $B$ at different equivalence ratios

Distributions of relative heat release rate of fuel B at different equivalence ratios is shown in Fig. 9. The curve between the two window is approximated by a 3rd order polynomial with parameters determined by values and slope of both sides of $\mathrm{CH}^{*}$ luminescence because $\mathrm{CH}^{*}$ image in this region is not recorded due to configuration of the combustor. At the lower equivalence 0.14 , the heat release near the trailing edge of cavity is more intense, but at the higher equivalence ratio of 0.17 , heat releasing in the region far downstream of the cavity (in the second window) is larger. To analysis the phenomenon, the ignition delay time of the blend fuel is calculated by using the detailed chemical kinetic mechanisms proposed by H. Wang [8]. Because the velocity near the trailing edge of cavity is almost the sonic, the temperature of air in this region is about $1640 \mathrm{~K}$ which is used in the calculation. The results show that the ignition delay time increases with the equivalence ratio increasing.

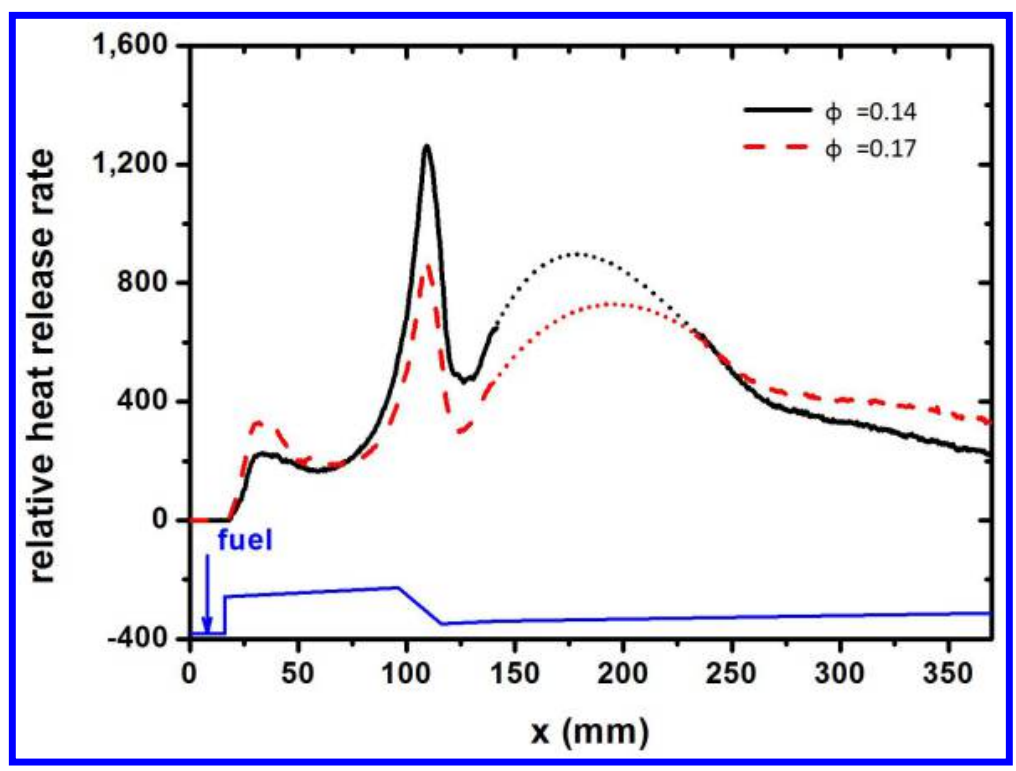

Fig. 9 Distributions of relative heat release ratio of fuel $B$ at different equivalence ratios

Fig. 10 gives distributions of wall pressure along the axis of combustor at different ratios. With a same position of peak of pressure, the pressure in the region downstream of the trailing edge of cavity at equivalent ratio 0.14 is slight higher that at equivalence ratio 0.17 , which is caused by the more intense heat release in the cavity region for the $\varphi=0.14$ case as discussed for Fig. 9 . 


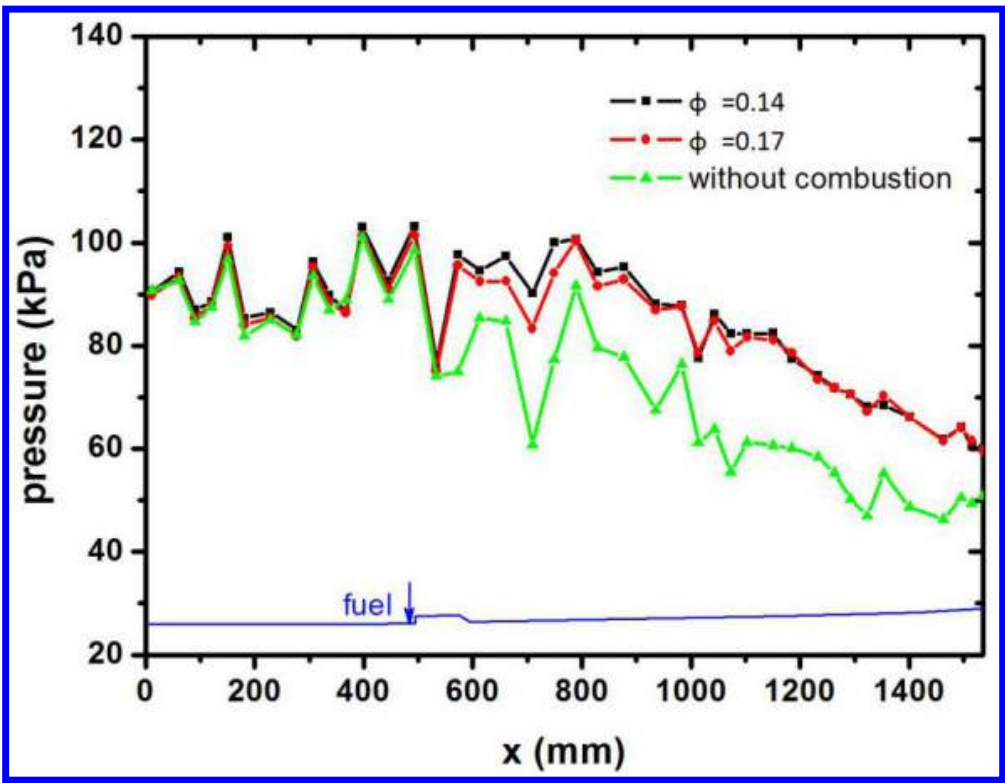

Fig. 10 Distributions of wall pressure of fuel $B$ at different equivalence ratios

\section{Conclusions}

In this paper, ignition and flame characteristics of ethylene and blend fuel (surrogate of cracked hydrocarbon fuels) are studied experimentally. $\mathrm{CH}^{*}$ luminance in the combustion is recorded by high-speed camera with a frame rate of $10000 \mathrm{fps}$, and the process of ignition and flame formation and propagation are captured. Meanwhile the image of $\mathrm{CH}^{*}$ luminance is one-dimensional treated along the axis of the combustor and the relative heat release rate is obtained. Distributions of relative heat release and flame characteristics are discussed and some conclusions are drawn as below:

1) The fuel is ignited by spark plug at the bottom of cavity and then the flame spread to the entire cavity, after which the flame is stabled around the trailing edge of cavity for small equivalence ratios. The ignition time of blend fuel is much longer that of ethylene at the same equivalence ratio.

2) With equivalence ratio increasing, the flame of ethylene moves upstream from the trailing edge of the cavity to the region upstream of fuel injection position, and the peak of relative heat release rate and the position that wall pressure begins to rise move upstream correspondingly, which resulting in a higher combustion efficiency.

3) The region of heat releasing of the blend fuel is much longer than that of ethylene and with equivalence ratio increasing, the flame pattern and distribution of blend fuel remain almost the same.

\section{Acknowledgments}

This work is funded by Natural Science Foundation of China under Contract No. 91441102.

\section{References}

[1] H. Huang, L.J. Spadaccini and D.R. Sobel, Fuel-Cooled Thermal Management for Advanced Aero-Engines, Journal of Engineering for Gas Turbines and Power, 126(2): 284-293, 2002.

- [2] Fengquan Zhong, Xuejun Fan, Gong Yu and Jiangguo li. Thermal cracking and heat sink capacity of aviatioin kerosene under supersonic conditions. Journal of Thermophysics and Heat Transfer, 25(3):450-456, 2011.

[3] Y. Hardalupas and M. Orain. Local measurements of the time-dependent heat releases rate and equivalence ratio using chemiluminescence emission from a flame. Combust. Flame, 139:188-207, 2004.

[4] Daniel J. Micka, Sean M. Torrez, and James F. Driscoll.Heat release distribution in a dual-mode scramjet combustor-measurements and modeling.16th AIAA/DLR/DGLR International Space Planes and Hypersonic Systems and Technologies Conference. AIAA 2009-7362.

[5] L. C. Haber and U. Vandsburger. A global reaction model for $\mathrm{OH}^{*}$ chemiluminescence applied to a laminar flat-flame burner. Combust. Sci. Tech.,175:1859-1891, 2003. 
[6] K. Wohl and F. Welty. Spectorphotometric traverses through flame fronts. Proc. Comb. Inst., 5:746-753, 1954.

[7] Hongbin Gu, Lihong Chen, Wang Dan, Xinyu Chang, Lizhi, Xilong Yu,Experimental investigation on coupling characteristics of cavity flame holder and strut jet, AIAA paper 2012-5961, 2012.

[8] H. Wang and A. Laskin, A comprehensive kinetic model of ethylene and acetylene oxidation at high temperatures, Process Report for an AFOSR New World Vista Program, 1998. 